(2)

OPEN ACCESS

\title{
Effect of autologous adipose-derived mesenchymal stem cell therapy in combination with autologous platelet-rich plasma in the treatment of elbow tendinopathy
}

\author{
Julien Freitag (D) , ${ }^{1,2,3}$ Kiran Shah, ${ }^{3}$ James Wickham, ${ }^{1}$ Abi Tenen ${ }^{2,3,4}$
}

${ }^{1} S$ chool of Biomedical Sciences, Charles Sturt University, Orange Campus, Orange, New South Wales, Australia

${ }^{2}$ Melbourne Stem Cell Centre, Box Hill North, Victoria, Australia ${ }^{3}$ Magellan Stem Cells, Box Hill North, Victoria, Australia ${ }^{4}$ School of Primary Health Care, Monash University, Notting Hill, Victoria, Australia

Correspondence to Professor Julien Freitag; julien.freitag@mscc.com.au

Accepted 31 May 2020
Check for updates

(c) BMJ Publishing Group Limited 2020. Re-use permitted under CC BY-NC. No commercial re-use. See rights and permissions. Published by BMJ.

To cite: Freitag J, Shah K, Wickham J, et al. BMJ Case Rep 2020;13:e234592. doi:10.1136/bcr-2020234592

\section{SUMMARY}

Tendinopathy is a common condition of both the athletic and general population and can be associated with significant pain and disability. The ability of mesenchymal stem cells (MSCs) to differentiate along a mesodermal cell lineage, including tenocytes, and secrete various bioactive regenerative and anti-inflammatory molecules has seen them considered as a future reparative therapy for tendinopathy. Preclinical trials with MSCs have shown promising positive functional and structural outcomes in several connective tissue related conditions. A 52-yearold male professional masters golfer presents with a clinical history of common extensor origin tendinopathy of the elbow. Subsequent formal ultrasound showed evidence of a large intrasubstance tear. The patient underwent intratendinous autologous adipose-derived MSC therapy in combination with autologous plateletrich plasma. Following treatment, the patient reported progressive improvement as measured by the validated Numeric Pain Rating Scale and Patient-Rated Tennis Elbow Evaluation score. Repeat imaging showed successful regeneration of tendon-like tissue.

\section{BACKGROUND}

Tendinopathy is a condition seen in both the athletic and general population and is commonly associated with significant pain and debility. ${ }^{1}$ Management options for tendinopathy include use of simple analgesics, oral anti-inflammatories, physiotherapy, corticosteroids and more recent interventions such as extracorporeal shockwave therapy and plateletrich plasma (PRP) injection to the affected site. These interventions have varying levels of evidence and success with lack of evidence of structural healing. Additionally, the use of corticosteroids has been questioned due to worse long-term outcomes in comparison to placebo injections. ${ }^{2}$ Recalcitrant cases of tendinopathy may require surgical intervention, which has a variable outcome and is complicated by a prolonged recovery and return to pre-injury activity.

Common extensor origin (CEO) tendinopathy was first described by Runge in 1873 and is commonly termed 'tennis elbow'. ${ }^{3}$ CEO tendinopathy is the most commonly diagnosed musculoskeletal injury of the elbow and affects 1\%-3\% of the population each year. ${ }^{4-6} \mathrm{Up}$ to $40 \%$ of tennis players will report symptoms of CEO tendinopathy. ${ }^{6}$

Causality of CEO tendinopathy is known to involve a number of factors, including overuse, strength deficits and training errors, resulting in observed tendon degenerative change within the extensor carpi radialis brevis and extensor digitorum communis at the lateral epicondyle. ${ }^{4}$ Current understandings of the process of tendinopathy suggests a model of degeneration and failed healing. ${ }^{7}$ While originally called tendinitis, this

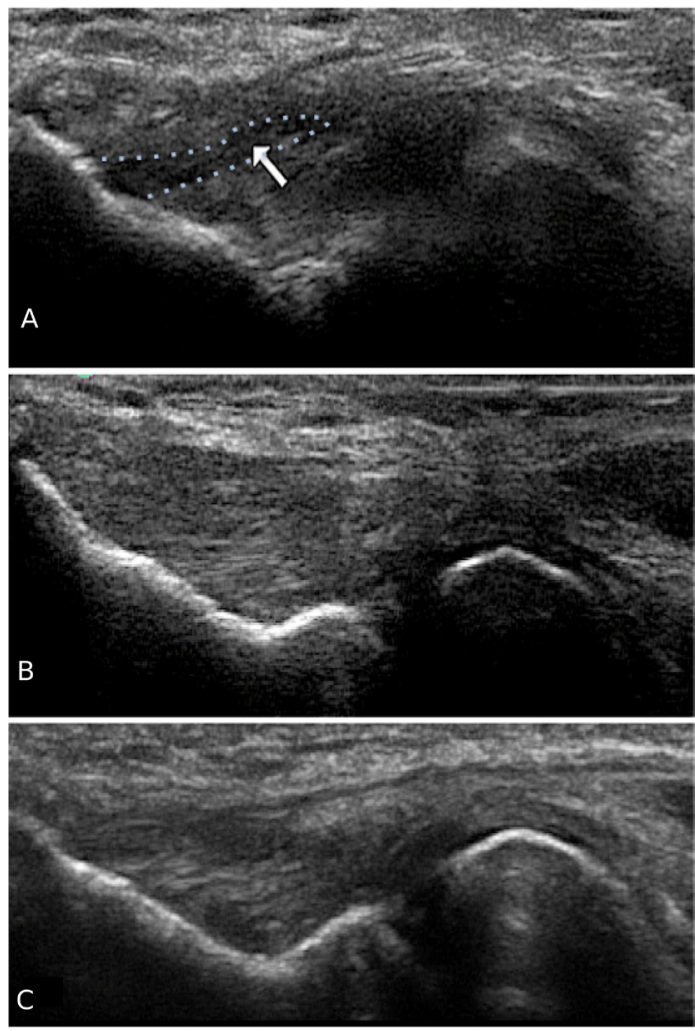

Figure 1 (A) Baseline ultrasound (US) showing marked common extensor origin tendinopathy with an intrasubstance tear with hypoechoic tissue pattern (arrow and outlined in blue). (B) Formal US at 18 months showing successful regeneration of tendon-like tissue at the past area of tendinopathy. (C) Formal US at 30 months indicating sustained structural improvement at long-term follow-up. 
name fell out of favour due to lack of inflammatory cell infiltrate within the tendon and yet more recent identification of inflammatory cytokines within and around areas of tendon degeneration has seen 'itis' re-emerge within the descriptive vernacular. ${ }^{8}$

The ability of mesenchymal stem cells (MSCs) to differentiate along a mesodermal cell lineage-including tenocytes-has seen them explored as a reparative therapy in musculoskeletal conditions. It is, however, now better understood that their mechanism of action is likely due to paracrine mechanisms through expression of cytokines and secretomes/exosomes, which directly influences the local micro-environment by modulation of the local immune response and also stimulating repair. ${ }^{9}$

Several preclinical trials on the use of MSCs in tendinopathy have shown positive functional and structural outcome results. ${ }^{1011}$ Despite these promising preclinical in vitro and in vivo results, there is limited clinical research published on the use of MSC therapy in tendinopathy. A recent systematic review found only four published clinical studies of level 4 evidence. ${ }^{12}$ Three of these studies used bone marrow concentrate techniques (which may have a less than $0.01 \%$ MSC population) and did not perform cell typing. ${ }^{13-15}$ A single study used allogeneic adiposederived MSCs (ADMSCs) with isolation and expansion, though only limited cell typing/characterisation was performed. ${ }^{16}$

This case study describes the successful use of isolated and expanded autologous ADMSCs in combination with PRP in the treatment of a severe elbow CEO tendinopathy.

\section{CASE PRESENTATION}

A 52-year-old male professional masters golfer presented with a painful right elbow. He had a history of previous common extensor tendinopathy, which had been treated with manual therapy, including physiotherapy and a corticosteroid injection. More recently, he had noted recurrence of pain with increasing pain and debility over the last 3 months. He was unable to grip without significant pain and this not only adversely affected his ability to play golf but also to perform simple activities of daily living. The patient had previously undergone successful autologous ADMSC therapy for symptomatic bilateral knee osteoarthritis under a human research ethics committee approved case series (Australian New Zealand Clinical Trials Registry: ACTRN12617000638336).

On examination, the patient was directly tender over his CEO. He had pain and weakness on wrist and middle finger extension. Upper limb neural tension testing was negative.

Formal radiological assessment using ultrasound (US) showed evidence of a large right elbow CEO intrasubstance tear, hypoechoic tendon pattern with loss of fibril continuity, associated florid neovascularisation and also fusiform thickening (figure 1A).

As the patient had recurrence of symptoms despite previous conventional therapy and rehabilitation, including a corticosteroid injection and physiotherapy, and as he was hopeful to prevent need for surgery and delayed return to professional golf, he enquired as to the possible role of MSCs in tendon repair. The current level of evidence of MSC therapy in the treatment of tendinopathy was discussed with the patient. Formal written information was provided regarding the use of and relative risks that may be associated with MSC therapy. Alternatives, including surgical repair, were discussed thoroughly. Prior to commencement of treatment, the patient completed formal written consent.

\section{INVESTIGATIONS}

Routine radiological US at baseline showed evidence of a large right elbow common extensor tendon intrasubstance tear with noted hypoechoic change within the tendon tissue (figure $1 \mathrm{~A}$ ). Repeat US was performed at 18 months and again at 30 months post commencement of ADMSC therapy (figure $1 \mathrm{~B}, \mathrm{C}$ ).

\section{TREATMENT}

\section{Autologous ADMSC preparation}

Harvest procedure

Adipose tissue is a rich source of MSCs. Previous research has indicated that ADMSCs have similar mesodermal lineage differentiation potential to other sources, including bone marrow. ${ }^{17} 18$

As previously highlighted, the patient had previously undergone abdominal liposuction as part of his participation in an ethics approved case series on the use of ADMSCs in knee osteoarthritis. The liposuction/harvest procedure has been formally described in past publications. ${ }^{19-21}$ In summary, approximately $200 \mathrm{~mL}$ of tumescent fluid (comprising of $30 \mathrm{~mL}$ of $2 \%$ lignocaine, $1 \mathrm{~mL}$ of $1: 1000$ epinephrine and $1 \mathrm{~mL}$ of $8.4 \%$ bicarbonate suspended in normal saline to a total volume of 1000 $\mathrm{mL}$ ) was infiltrated throughout the area of abdominal fat via two lateral abdominal incisions. Using a $4 \mathrm{~mm}$ lipoaspirate cannula, $60 \mathrm{~mL}$ of lipoaspirate was collected within a sterile medical grade single use Shippert Tissu-Trans Collection Filter container (Shippert Medical, Colorado, USA) and transferred directly to a clean room laboratory on site (Magellan Stem Cells, Melbourne, Australia).

\section{Isolation and expansion of MSCs}

The isolation and expansion of ADMSCs was performed within a certified clean room laboratory with equivalent of $>$ ISO 5 air quality and all manual tasks were performed additionally within class II biological safety cabinets. The formal process of isolation and expansion has previously been described in our past publications. ${ }^{19-21}$

Isolated ADMSCs were suspended and stored in clinical grade cryoprotectant media. Cryopreservation was achieved using a validated controlled rate freezing method. ${ }^{22} 23$

\section{Characterisation and sterility testing}

ADMSCs were characterised as per criteria established by the International Society of Cellular Therapy. ${ }^{24}$ Flow cytometry fluorescence activated cell sorting analysis assessed for the presence of MSC surface markers (see table 1).

Independent sterility testing for microbial growth/contamination was completed after isolation and expansion.

Table 1 Fluorescence activated cell sorting surface marker analysis showing results consistent with mesenchymal stem cells as per the International Society of Cellular Therapy guidelines

\begin{tabular}{|c|c|c|c|c|c|c|c|}
\hline & \multicolumn{3}{|c|}{ Positive markers } & \multicolumn{4}{|c|}{ Negative markers } \\
\hline & CD90+ & CD73+ & CD105+ & CD14+ & CD19+ & CD34+ & CD45+ \\
\hline Percentage & 98.44 & 99.87 & 99.12 & 0.74 & 0.09 & 0.91 & 0.8 \\
\hline
\end{tabular}




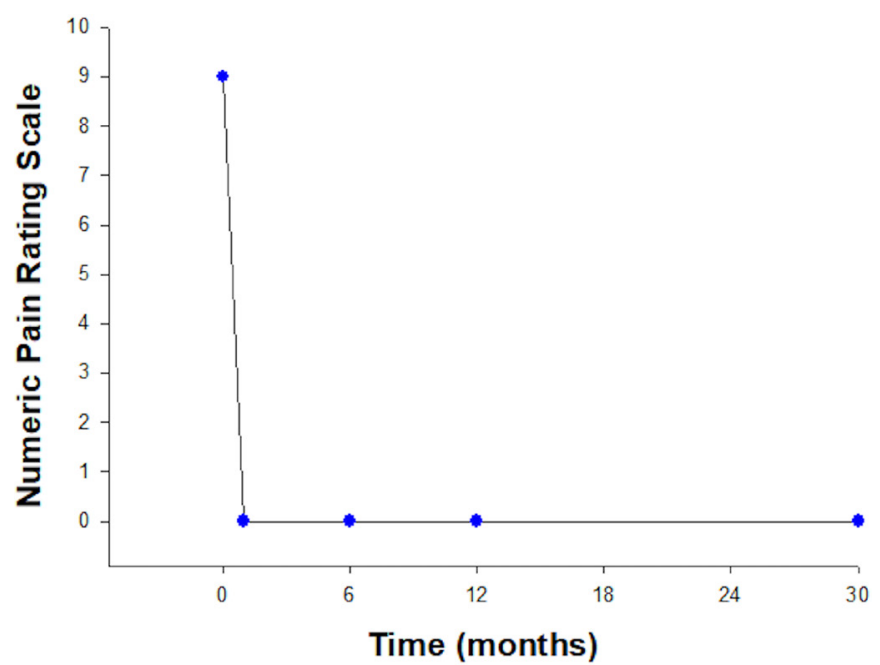

Figure 2 Numeric Pain Rating Scale. Pain scores showed a marked and sudden reduction in pain following ADMSC, which was maintained throughout follow-up.

\section{ADMSC injectable preparation}

A sterile water bath was used to thaw the ADMSCs once taken out of cryopreservation. Using a method of repeat centrifugation and washing in chilled phosphate-buffered saline, the cryoprotectant was removed leaving a cell pellet. The ADMSC pellet was re-suspended in Hartmann's solution to a total of $1 \mathrm{~mL}$. A Muse Cell Analyser (Merck, Millipore, USA) was used to confirm cell number and viability. The patient received a total of 10 million ADMSCs (viability 97\%) into the affected site.

The ADMSC therapy was combined with a preparation of autologous white-cell-rich PRP. Autologous PRP was prepared using a double spin method. Autologous blood $(25.5 \mathrm{~mL})$ was withdrawn from the patient via venepuncture and collected in $3 \times 8.5 \mathrm{~mL}$ BD Vacutainers (BD, Franklin Lakes, New Jersey, USA) containing ACD (citric acid $8.0 \mathrm{~g} / \mathrm{L}$, trisodium citrate $22.0 \mathrm{~g} / \mathrm{L}$ and dextrose $24.5 \mathrm{~g} / \mathrm{L}$ ). Using a benchtop centrifuge, the blood underwent an initial soft spin at $1000 \mathrm{rpm}$ for $8 \mathrm{~min}$.

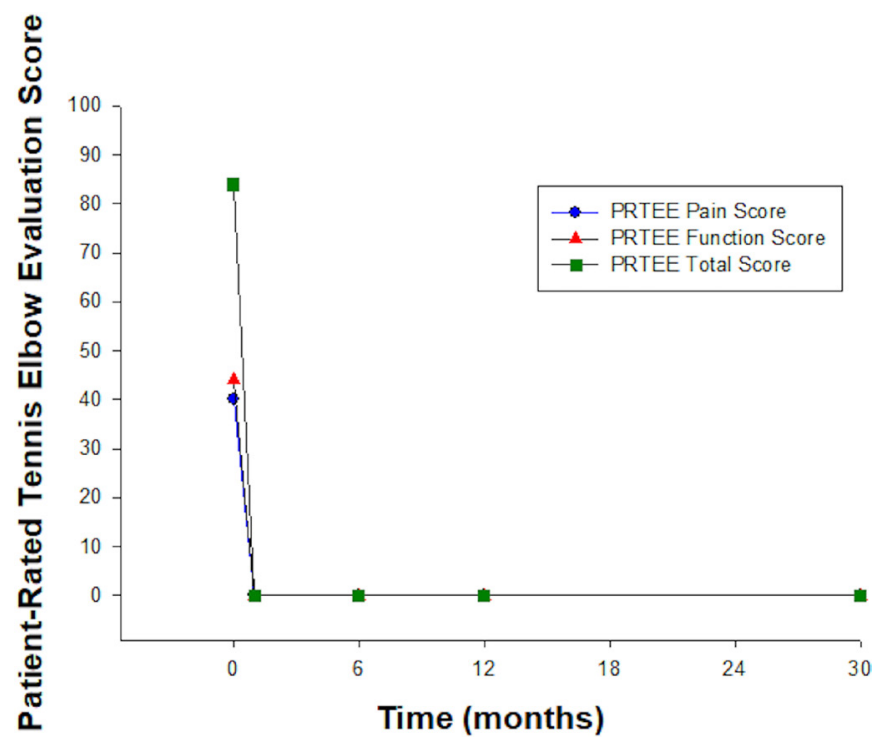

Figure 3 Patient-Rated Tennis Elbow Evaluation. Scores showed rapid improvement in pain and function with no functional impairment by 1 month of treatment.
Platelet-poor plasma (PPP) was withdrawn to the level of the red blood cell layer and placed in a single sterile vacutainer, which underwent a second hard spin at $3500 \mathrm{rpm}$ for $2 \mathrm{~min}$ resulting in formation of a platelet plug and PPP. PPP was withdrawn to the level of $10 \mathrm{~mm}$ and discarded. The remaining PPP and platelet plug were reconstituted using gentle manual agitation resulting in $1 \mathrm{~mL}$ of white-cell-rich PRP.

\section{ADMSC treatment protocol and injection method}

All injections were performed using an aseptic technique and under direct visualisation with the use of US. Two millilitres of local anaesthetic ( $2 \%$ lidocaine) was infiltrated superficial to the tendon. The ADMSCs were injected under US guidance into the area of CEO tendinopathy and with specific focus to the area of hypoechoic change and tendon fibril discontinuity/tearing. Following this, the additional $1 \mathrm{~mL}$ of autologous white-cell-rich PRP was injected to the same site.

\section{Outcome measures/analysis}

Pain and functional outcome was assessed at baseline, 1, 6, 12 and 30 months, using the following validated outcome measures.

1. Numeric Pain Rating Scale: the patient rated his elbow pain over the previous week on a scale of 0 (no pain) to 10 (maximal pain).

2. Patient-Rated Tennis Elbow Evaluation (PRTEE): the PRTEE score is a validated and reproducible assessment of chronic lateral elbow tendinopathy. ${ }^{25}$ The PRTEE consists of a twopart assessment: pain and function subscales. Both subscales are scored on a scale of $0-50$ with 50 indicating maximal pain and loss of function. These subscales are added together to provide a total score out of 100 .

All questionnaires were completed online and remotely using the software programme Clinical Intelligence (Clinical Intelligence, Melbourne, Australia).

Structural outcome was assessed using US imaging at baseline, 18 months and at final data collection at 30 months.

\section{OUTCOME AND FOLLOW-UP}

\section{Pain and functional outcome}

The patient experienced rapid pain and functional improvement following ADMSC therapy. The pain score improved from 9 out of 10 to 0 at 1 month and remained 0 at completion of follow-up at 30 months (see figure 2).

PRTEE scores at baseline indicated significant impairment. Both PRTEE pain and function scores improved rapidly and indicated no functional impairment from 1 month until completion of follow-up at 30 months (see figure 3 ).

\section{Structural outcome}

Repeat US performed at 18 months and again at 30 months showed complete tissue infill at the site of previous hypoechoic change and fibril discontinuity (figure 1). All neovascularisation had resolved.

\section{Complications and adverse events}

No significant adverse events were noted throughout follow-up. The patient observed discomfort at the time of ADMSC and PRP injection to the site of injury, though this was self-limiting and did not require analgesics.

\section{DISCUSSION}

Tendinopathy is considered an overuse injury whereby there is disruption of the normal tendon structure and a failed healing 
response. Despite the benefits seen in treatment modalities, including use of non-steroidal anti-inflammatories, corticosteroid injections and physiotherapy-based rehabilitation, there remain cases unresponsive to conventional therapies. In addition to this, there is a paucity of evidence of structural healing with current conservative treatment modalities. MSCs, with an ability to differentiate along a mesodermal lineage, have emerged as a future regenerative treatment option for musculoskeletal disorders, including tendinopathy.

While preclinical animal trials have shown considerable promise, there is limited clinical research. A recent systematic review of the use of stem cell therapy for tendon disorders concluded that of the only four trials identified, there was a high risk of bias and all studies failed to appropriately characterise the cell population and quantify cell count and viability. ${ }^{12}$

In this single case report, the use of ADMSCs resulted in rapid clinical improvements in pain and function in severe CEO tendinopathy of a professional masters golfer. Pain scores reduced to 0 by 1 month of follow-up, with the patient remaining asymptomatic throughout the remainder of follow-up. This improvement was reflected in PRTEE pain and function scores.

Repeat US analysis at 18 months and again at 30 months showed successful regenerative healing at the site of tendinopathy with tissue ingrowth and resolution of the intrasubstance tear.

In this case study, ADMSC therapy was combined with the use of PRP. Previous research has suggested that growth factors derived from PRP may assist in cell migration, proliferation and extracellular matrix synthesis. ${ }^{26}$ In addition, the in vitro combination of PRP with MSCs has been shown to result in collagen type I expression and MSC differentiation along a tenocyte lineage. ${ }^{27}$ While the addition of PRP was based on preclinical evidence of the supportive role of blood-derived growth factors on MSC action, it is recognised that previous studies have shown symptomatic improvement in tendinopathy following PRP in isolation. ${ }^{28}$ While improvements observed in this case study may be attributable to PRP alone, it is the authors' experience that PRP therapy is associated with slower and less complete symptom improvement and typically lack of structural improvement on follow-up imaging.

The mechanism of action of MSCs in tissue repair is debatable. Previous research suggests that few cells remain in situ long-term after implantation, indicating that stem cells may not influence repair through differentiation into tenocytes. It is now more commonly accepted that MSCs likely stimulate repair through paracrine expression of cytokines, secretomes/exosomes and also cell-to-cell interaction. ${ }^{9}{ }^{9}$

This single case report highlights the potential of MSCbased therapies in the treatment of tendinopathy. More formal controlled trials are warranted to determine if this result is reproducible among a larger population of patients. Additional imaging modalities such as MRI would be of benefit in

\section{Learning points}

Tendinopathy is a common condition associated with significant pain and disability.

- Current conservative and surgical management of tendinopathy has shown inconsistent success rates.

- The novel use of autologous adipose-derived mesenchymal stem cell therapy resulted in rapid clinical improvement in pain and function and tissue repair at long-term follow-up. assessment of structural change. Use of cell labelling techniques may allow for the assessment of cell migration and integration and would give additional information regarding the proposed mechanism of action.

Acknowledgements The authors would like to acknowledge the following people for their contribution to the case study: Renee Castelluccio, Lesley-ann Kelly, Lucinda Kenihan, Melissa Grogan and Ellee Picken, for assistance in data acquisition.

Contributors JF is a sport and exercise medicine physician and the treating physician of the patient presented in the case report. JF, KS, JW and AT were involved in the data acquisition, analysis of data, drafting of the report, have read and approved the final manuscript, agreed to be accountable for the article and ensure that all questions regarding the integrity of the article are investigated and resolved.

Funding The authors have not declared a specific grant for this research from any funding agency in the public, commercial or not-for-profit sectors.

Competing interests JF and AT are affiliated with Magellan Stem Cells and are members of Magellan Stem Cells' Clinical and Scientific Advisory Board. KS is affiliated with and the chief scientific officer of Magellan Stem Cells.

\section{Patient consent for publication Obtained.}

Provenance and peer review Not commissioned; externally peer reviewed.

Open access This is an open access article distributed in accordance with the Creative Commons Attribution Non Commercial (CC BY-NC 4.0) license, which permits others to distribute, remix, adapt, build upon this work non-commercially, and license their derivative works on different terms, provided the original work is properly cited and the use is non-commercial. See: http://creativecommons.org/ licenses/by-nc/4.0/.

\section{ORCID iD}

Julien Freitag http://orcid.org/0000-0001-6701-4368

\section{REFERENCES}

1 Maffulli N, Wong J, Almekinders LC. Types and epidemiology of tendinopathy. Clin Sports Med 2003;22:675-92.

2 Scott A, Khan KM. Corticosteroids: short-term gain for long-term pain? Lancet 2010;376:1714-5.

3 Runge F. Zur genese und behandlung des schreibekrampfes. Berl Klin Wochenschr 1873;10:245-8.

4 Nirschl RP. Elbow tendinosis/tennis elbow. Clin Sports Med 1992;11:851-70.

5 Verhaar JA, elbow T. Tennis elbow. anatomical, epidemiological and therapeutic aspects. Int Orthop 1994;18:263-7.

6 Gabel GT. Acute and chronic tendinopathies at the elbow. Curr Opin Rheumatol 1999;11:138-43.

7 Kraushaar BS, Nirschl RP. Tendinosis of the elbow (tennis elbow). clinical features and findings of histological, immunohistochemical, and electron microscopy studies. J Bone Joint Surg Am 1999;81:259-78.

8 Rees JD, Stride M, Scott A. Tendons--time to revisit inflammation. Br I Sports Med 2014:48:1553-7.

9 Lui PPY. Stem cell technology for tendon regeneration: current status, challenges, and future research directions. Stem Cells Cloning 2015:8:163-74.

10 Young RG, Butler DL, Weber W, et al. Use of mesenchymal stem cells in a collagen matrix for Achilles tendon repair. J Orthop Res 1998:16:406-13.

11 Chong AKS, Ang AD, Goh JCH, et al. Bone marrow-derived mesenchymal stem cells influence early tendon-healing in a rabbit Achilles tendon model. J Bone Joint Surg Am 2007:89:74-81.

12 Pas HIMFL, Moen MH, Haisma HJ, et al. No evidence for the use of stem cell therapy for tendon disorders: a systematic review. Br J Sports Med 2017;51:996-1002.

13 Ellera Gomes JL, da Silva RC, Silla LMR, et al. Conventional rotator cuff repair complemented by the aid of mononuclear autologous stem cells. Knee Surg Sports Traumatol Arthrosc 2012;20:373-7.

14 Hernigou P, Flouzat Lachaniette $\mathrm{CH}$, Delambre J, et al. Biologic augmentation of rotator cuff repair with mesenchymal stem cells during arthroscopy improves healing and prevents further tears: a case-controlled study. Int Orthop 2014;38:1811-8.

15 Pascual-Garrido C, Rolón A, Makino A. Treatment of chronic Patellar tendinopathy with autologous bone marrow stem cells: a 5-year-followup. Stem Cells Int 2012;2012:1-5

16 Lee SY, Kim W, Lim C, et al. Treatment of lateral epicondylosis by using allogeneic adipose-derived mesenchymal stem cells: a pilot study. Stem Cells 2015;33:2995-3005.

17 Im G-I, Shin Y-W, Lee K-B. Do adipose tissue-derived mesenchymal stem cells have the same osteogenic and chondrogenic potential as bone marrow-derived cells? Osteoarthritis Cartilage 2005;13:845-53.

18 Peng L, Jia Z, Yin X, et al. Comparative analysis of mesenchymal stem cells from bone marrow, cartilage, and adipose tissue. Stem Cells Dev 2008;17:761-74. 
19 Freitag J, Shah K, Wickham J, et al. The effect of autologous adipose derived mesenchymal stem cell therapy in the treatment of a large osteochondral defect of the knee following unsuccessful surgical intervention of osteochondritis dissecans - a case study. BMC Musculoskelet Dis 2017;18:298.

20 Freitag J, Li D, Wickham J, et al. Effect of autologous adipose-derived mesenchymal stem cell therapy in the treatment of a post-traumatic chondral defect of the knee. BMJ Case Rep 2017;2017. doi:10.1136/bcr-2017-220852. [Epub ahead of print: 15 Oct 2017].

21 Freitag J, Bates D, Wickham J, et al. Adipose-Derived mesenchymal stem cell therapy in the treatment of knee osteoarthritis: a randomized controlled trial. Regen Med 2019:14:213-30.

22 Goh BC, Thirumala S, Kilroy G, et al. Cryopreservation characteristics of adiposederived stem cells: maintenance of differentiation potential and viability. J Tissue Eng Regen Med 2007;1:322-4.

23 Martinello T, Bronzini I, Maccatrozzo L, et al. Canine adipose-derived-mesenchymal stem cells do not lose stem features after a long-term cryopreservation. Res Vet Sci 2011;91:18-24.
24 Dominici M, Le Blanc K, Mueller I, et al. Minimal criteria for defining multipotent mesenchymal stromal cells. The International Society for cellular therapy position statement. Cytotherapy 2006;8:315-7.

25 Rompe JD, Overend TJ, MacDermid JC. Validation of the patient-rated tennis elbow evaluation questionnaire. J Hand Ther 2007;20:3-11.

26 Qian Y, Han Q, Chen W, et al. Platelet-Rich plasma derived growth factors contribute to stem cell differentiation in musculoskeletal regeneration. Front Chem 2017:5:89.

27 Changsuo X, Hui H, Chao W, et al. Platelet-Rich plasma affects proliferation and collagen production in mesenchymal stem cells. J Biomater Tissue Eng 2018;8:750-5.

28 Fitzpatrick J, Bulsara MK, O'Donnell J, et al. The effectiveness of platelet-rich plasma injections in gluteal tendinopathy: a randomized, double-blind controlled trial comparing a single platelet-rich plasma injection with a single corticosteroid injection. Am J Sports Med 2018;46:933-9.

29 Caplan Al. Why are MscS therapeutic? new data: new insight. J Pathol 2009:217:318-24.

Copyright 2020 BMJ Publishing Group. All rights reserved. For permission to reuse any of this content visit https://www.bmj.com/company/products-services/rights-and-licensing/permissions/

BMJ Case Report Fellows may re-use this article for personal use and teaching without any further permission.

Become a Fellow of BMJ Case Reports today and you can:

- Submit as many cases as you like

- Enjoy fast sympathetic peer review and rapid publication of accepted articles

- Access all the published articles

- Re-use any of the published material for personal use and teaching without further permission

Customer Service

If you have any further queries about your subscription, please contact our customer services team on +44 (0) 2071111105 or via email at support@bmj.com.

Visit casereports.bmj.com for more articles like this and to become a Fellow 